\title{
ESTIMATIVA DA ABUNDÂNCIA RELATIVA DE CORVINA NA COSTA CENTRO-SUL DO BRASIL *
}

\author{
(Recebido em 2/1/1964) \\ A. E. A. de M. Vazzoler \\ Instituto Oceanográfico da Universidade de São Paulo
}

\section{SYNOPSIS}

The aim of this paper is to evaluate the apparent abundance of the croaker (Micropogon furnieri) along the central and southern coast of Brazil (from $23^{\circ} 50^{\prime} \mathrm{S}$ to $35^{\circ} \mathrm{S}$ ). The data on catch and effort of the fish taken in the same area and at the same time, with different gear, are analysed from January 1959 to December 1962.

The different gears used were reduced to the same level of efficiency, and the apparent abundance was estimated according to the fishing area (area I - from $23^{\circ} 50^{\prime} \mathrm{S}$ to $26^{\circ} \mathrm{S}$, and area II - from $26^{\circ} \mathrm{S}$ to $35^{\circ} \mathrm{S}$ ), by quarters and by year.

The results allow us to draw the following conclusions:

1 - There is a tendency of increase of the apparent abundance from the beginning to the end of each year and of decrease in following years, in both areas. The decrease is greater in area II.

2 - The levels of apparent abundance, in both areas, was very different. The level in area II is higher.

3 - Variations in the availability during the year, were observed. Data suggest that they are determined in area I by extrinsic factors, and in area II by intrinsic factors.

4 - Different responses of the stock, in both areas, to fishing intensity was verified, supporting the hypothesis of occurrence of two different croaker stocks. The stock of area I probably has reached a state of equilibrium with the fishery while in area II the stock has not yet reached this stage.

\section{INTRODUÇÃO}

$\mathrm{Na}$ estimativa da densidade de uma população natural, a pesca comercial pode ser considerada como uma fonte de amostragem dessa população, sendo que a produção por unidade de esfôrço reflete, até certo ponto, as variações da densidade relativa.

A densidade e abundância relativas de uma população natural estão relacionadas com as verdadeiras densidade e abundância, pela disponibilidade.

* Os dados utilizados na preparacão dêste trabalho foram cedidos pelo "Grupo de
Pesquisas sôbre a Pesca Marítima", a quem agradecemos.

Publ. ne 203 do Inst. Ocean. da USP. 
É conveniente conceituar densidade, abundância e disponibilidade.

Densidade é o pêso (ou número) total de indivíduos por unidade de área ou volume. Segundo Marr (1951), abundância é o pêso (ou número) total de peixes na população e, disponibilidade é o grau (porcentagem) em que a população de peixes é acessível à pesca. $\mathrm{O}$ têrmo disponibilidade abrange dois conceitos: 1) os peixes não podem ser capturados devido a seu comportamento, e 2) os peixes não podem ser pescados devido a fatôres que afetam a aplicação do esfôrço de pesca. Êsses fatôres são denominados por Marr (op. cit.) de intrínsecos e extrínsecos, respectivamente.

Vazzoler \& Sá (1963) analisaram as variações da densidade relativa de corvina na costa centro-sul do Brasil, através das variações da produção por unidade de esfôrço dos diferentes tipos de aparelhos, que operaram nessa área, durante o período 1959/62.

Entretanto, para melhor acompanhar as variações de abundância, oferece maior interêsse computar um índice combinado, que nos forneça essas variações em unidades padronizadas de esfôrço, suscetíveis de serem comparadas de período para período. Isso porque, em primeiro lugar, diferentes tipos de aparelhos operando nas mesmas condições de abundância, apresentam eficiências diferentes e, em segundo lugar, outras diferenças surgem quando consideramos os barcos grandes, que podem operar em regiões de alta concentração de peixes. Essas diferenças podem, entretanto, ser anuladas; as primeiras por fatôres de correção de eficiência e, as segundas, levando-se em conta apenas as pescarias que se realizaram ao mesmo tempo, num mesmo local.

\section{MATERIAL E MÉTODOS}

Foram utilizados os dados de desembarque e esfôrço referentes à corvina capturada entre as latitudes $23^{\circ} 50^{\circ}$ 'S e $35^{\circ} \mathrm{S}$, numa faixa de aproximadamente 30 milhas náuticas, pelos diferentes tipos de aparelhos (Vazzoler \& Sá, 1963), durante o período de janeiro de 1959 a dezembro de 1962 . Foram selecionados apenas os dados referentes às capturas realizadas numa mesma área e ao mesmo tempo, para eliminar as diferenças que podem ser introduzidas pela atuação dos diferentes aparelhos em áreas de densidades distintas.

Dêsse modo, as conclusões obtidas pela análise dos dados acima, limitam-se ao período 1959-1962, não sendo possível generalizá-las para outros períodos.

Seguindo o mesmo critério usado por Vazzoler \& Sá (op. cit.), a zona de pesca da corvina foi dividida em duas áreas (área I de $23^{\circ} 50^{\prime} \mathrm{S}$ a $26^{\circ} \mathrm{S}$ e área II - de $26^{\circ} \mathrm{S}$ a $35^{\circ} \mathrm{S}$ ) e os dados foram agrupados por trimestres e por ano. 
A pesca por unidade padronizada de esfôrço (abundância relativa) foi obtida dividindo-se o total desembarcado, proveniente das áreas comuns a todos os tipos de aparelhos, pelo esfôrço total padronizado (intensidade relativa de pesca), no nível de eficiência dos "trawlers" de porta médios e grandes. Êste esfôrço foi obtido, mediante a soma dos produtos do esfôrço de cada tipo de aparêlho, incluído na estimativa, pelo fator de correção de eficiência, constante para cada tipo de aparêlho.

O método para o cálculo dos fatôres de correção de eficiência e seu emprêgo na padronização do esfôrço está descrito em Shimada \& Schaefer (1956).

\section{RESULTADOS}

Na Figura 1, temos a representação gráfica das variações triaparelhos, dos fatôres de correção de eficiência, por área, para. os períodos de três meses e de um ano.

\begin{tabular}{|c|c|c|c|c|c|c|}
\hline & Trimestres & TPoMG & TPG & TPMG & TPP & TPoP \\
\hline \multirow{3}{*}{\begin{tabular}{l}
8 \\
\multirow{1}{*}{}
\end{tabular}} & 10 & 1 & 245,5 & 3,9 & 3,1 & 1,9 \\
\hline & 29 & 1 & 158,9 & 2,8 & 3,3 & 1,7 \\
\hline & 39 & 1 & - & 13,0 & 12,8 & 1,0 \\
\hline \multirow[t]{2}{*}{ I } & $4^{\circ}$ & 1 & - & 2,8 & 2,5 & 3,2 \\
\hline & 19 & 1 & 13,8 & 3,9 & - & - \\
\hline \multirow{2}{*}{\begin{tabular}{l}
\multirow{2}{*}{} \\
के
\end{tabular}} & 2 。 & 1 & 2,3 & 8,3 & - & - \\
\hline & $3^{\circ}$ & 1 & 2,7 & 1,6 & - & - \\
\hline \multirow[t]{2}{*}{ II } & 40 & 1 & 7,0 & 2,6 & - & - \\
\hline & Anual & TPoMG & TPG & TPMG & TPP & TPoP \\
\hline & Area I & 1 & 15,4 & 7,2 & 6,6 & 4,8 \\
\hline & Área II & 1 & 8,4 & 5,2 & - & - \\
\hline
\end{tabular}

TPoMG $=$ "trawlers" de porta médios e grandes

TPG = "trawlers" de parelhas grandes

TPMG = "trawlers" de parelhas médias e grandes

TPP $=$ "trawlers" de parelhas pequenas

TPoP $=$ "trawlers" de porta pequenos

Na Tabela I, temos a representação gráfica das variações trimestrais da produção total, da intensidade relativa de pesca e da abundância relativa, por área e por trimestre. Pode-se observar 

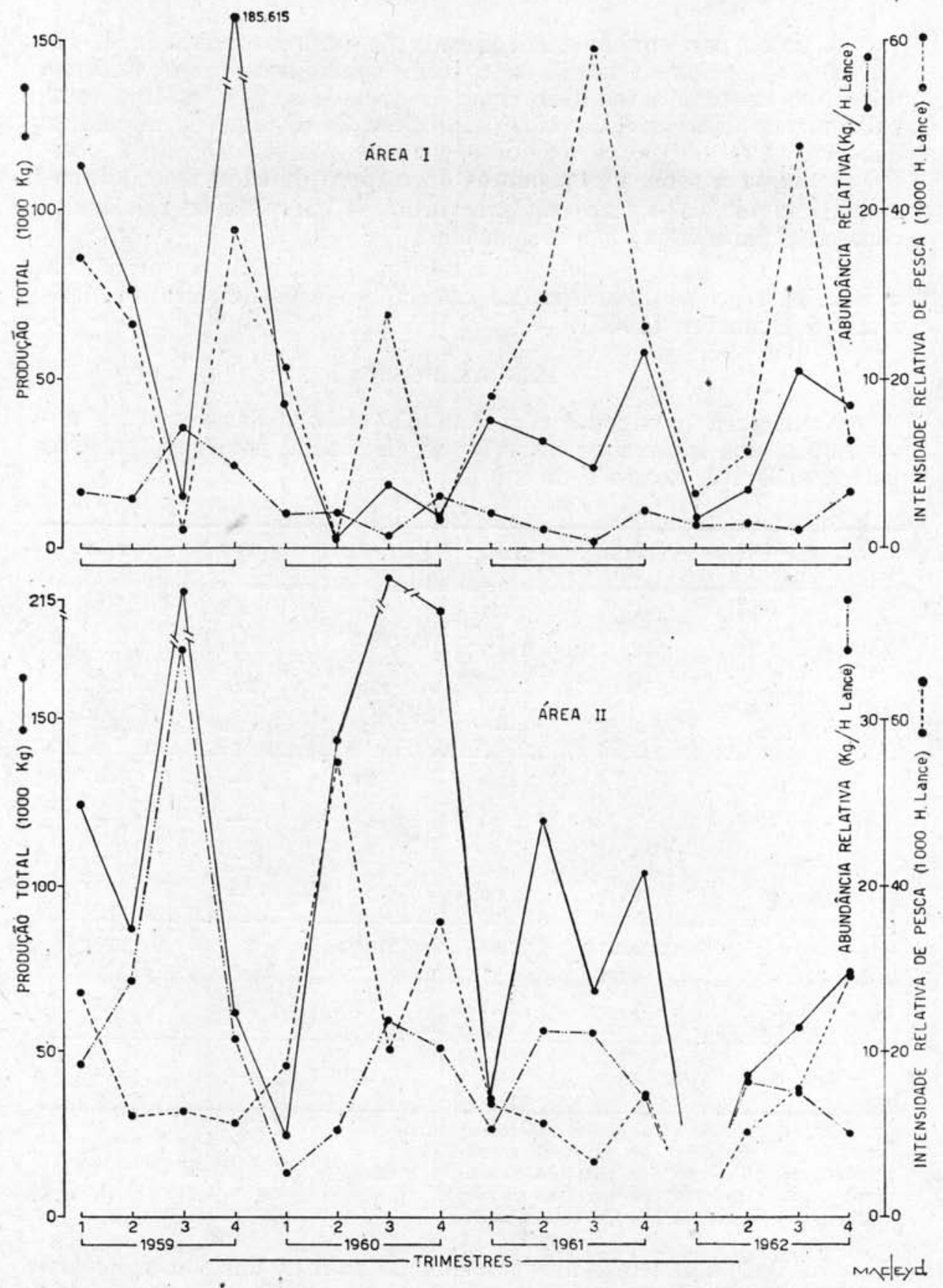

Fig. 1 - Variações trimestrais da prođução total, da intensidade relativa de pesca e da abundância relativa, por área, para o periodo 1959 a 1962. 

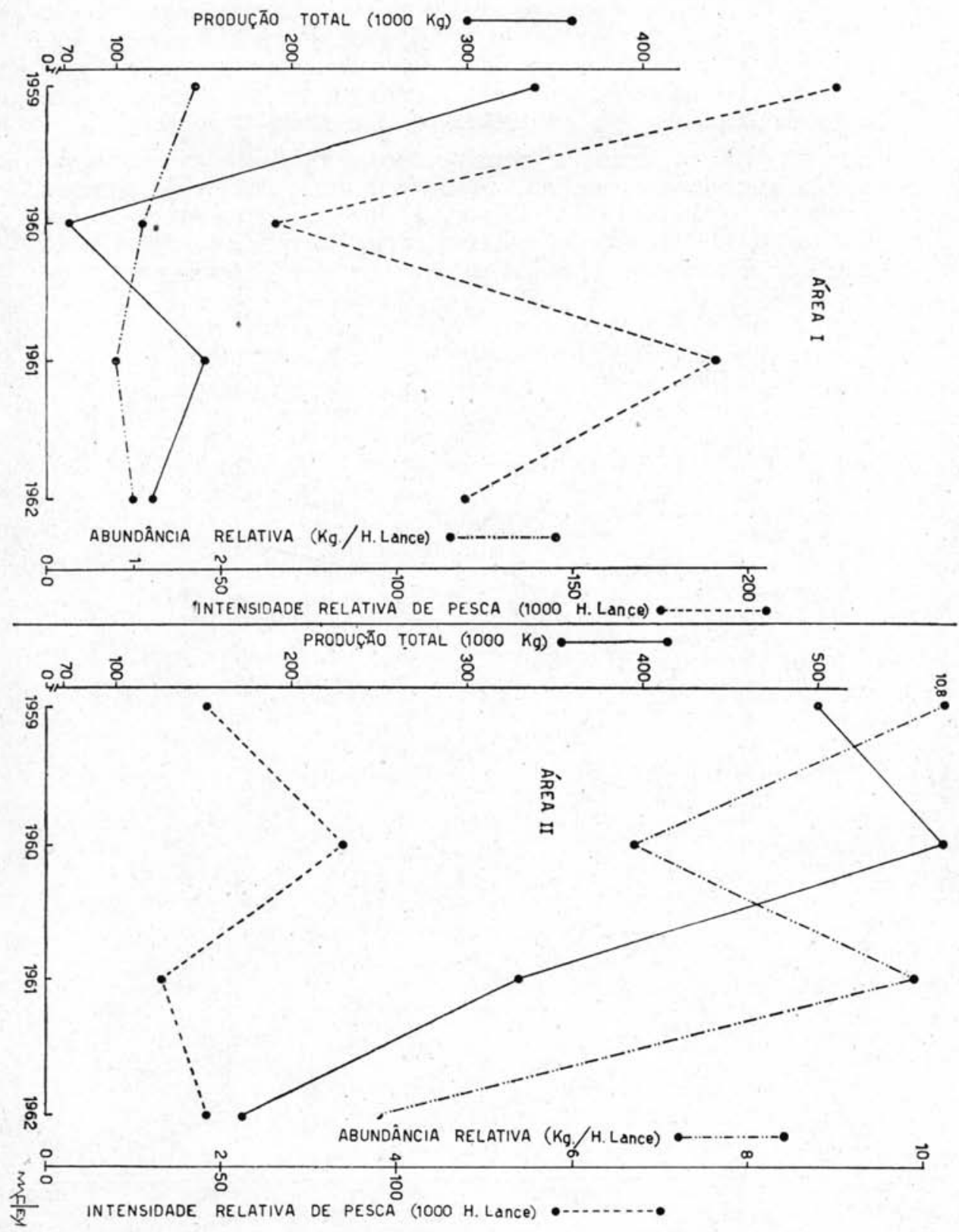

Fig. 2 - Variaçōes anuais da abundância relativa, da intensidade relativa de pesca e da produção total, por área, para o período 1959 a 1962. 
que houve tendência a aumento da abundância relativa do início para o fim do ano, em todos os anos e nas duas áreas, com exceção de 1962, área II. A intensidade relativa de pesca apresentou tendências, que variaram de ano para ano, nas duas áreas. A produção total apresentou tendência a aumentar do início para o fim de cada ano, com exceção de 1960, área I e 1959, área II.

$\mathrm{Na}$ Figura 2, temos a representação gráfica das variações anuais da abundância relativa, da intensidade relativa de pesca e da produção total, por área. Notamos que nas duas áreas a tendência, tanto da abundância relativa como da produção total e da intensidade relativa de pesca, é a de decrescer de ano para ano,

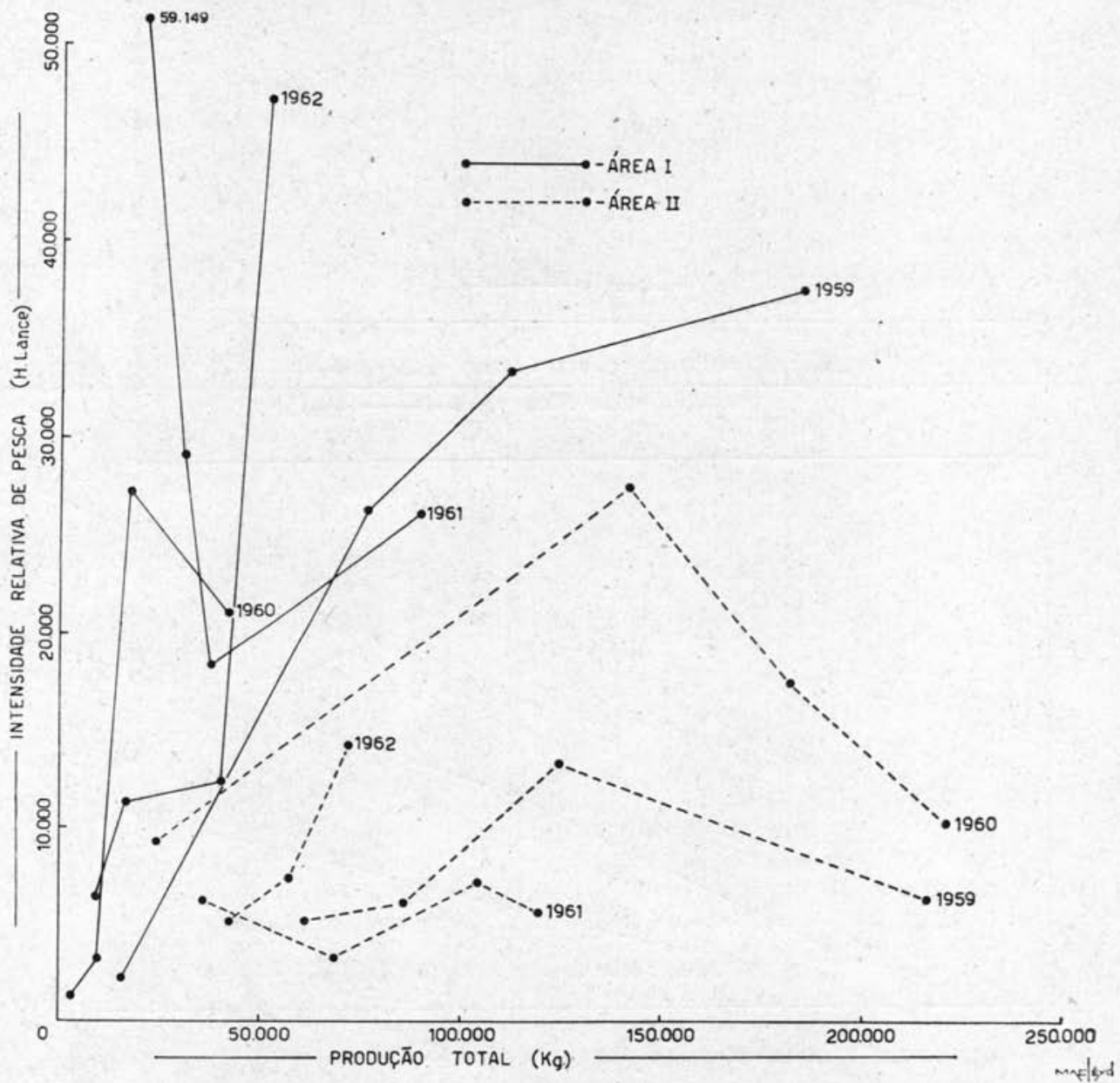

Fig. 3 - Relação entre os valôres trimestrais de produção total e intensidade relat!va de pesca, por área, para o período 1959 a 1962. 
sendo que para a área II essa queda é muito mais acentuada. Observamos, ainda, que o nível de abundância relativa na área II é muito mais elevado do que o da área I, ocorrendo o mesmo com os níveis de produção total. A intensidade relativa de pesca apresenta nível inferior na área II.

Na Figura 3, temos a relação entre os valôres trimestrais de produção total e intensidade relativa de pesca, para as duas áreas e por ano. Observamos que na área II não há relação entre produção e intensidade de pesca; ao contrário, para a área I notamos que, à medida que aumenta a intensidade de pesca, há aumento na produção total. Para uma mesma intensidade de pesca a produção na área II é sempre maior.

Na Figura 4, temos a relação entre os valôres trimestrais de produção total e abundância relativa. Notamos que, para a área I, não há relação entre abundância relativa e produção total; para a área II, entretanto, notamos que, à medida que aumenta a abundância, há aumento da produção total.

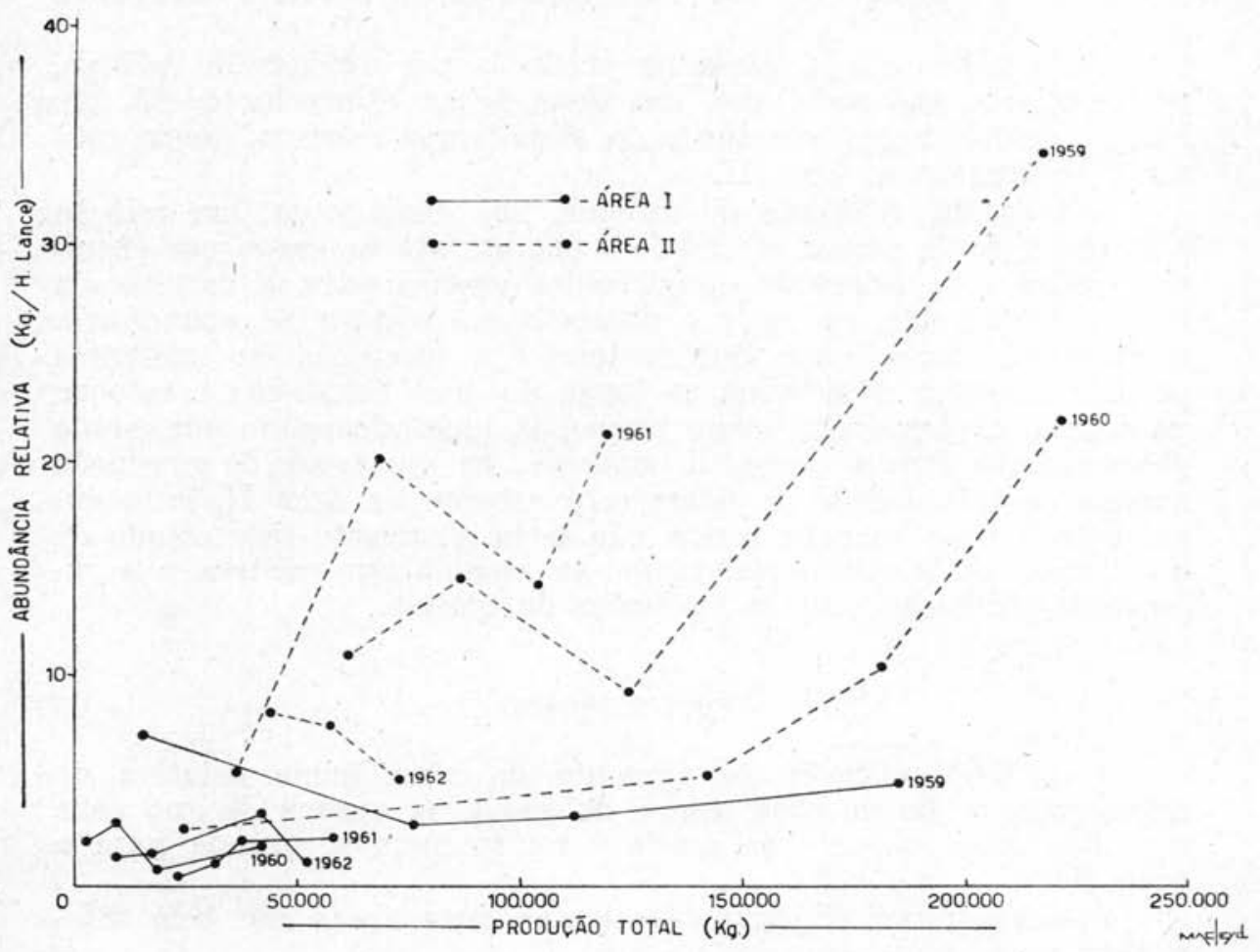

Fig. 4 - Relação entre os valôres trimestrais de producăo total e abundância relativa, por área, para o período 1959 a 1962. 


\section{DISCUSSÃO}

A tendência da abundância relativa de aumentar do início para o fim do ano, nas duas áreas, demonstra que as variações da produção por unidade de esfôrço, verificada para os vários tipos de aparelhos, durante o ano (Vazzoler \& Sá, 1963), são devidas a variações de disponibilidade. Vimos que na área I há paralelismo entre produção total e intensidade relativa de pesca, sendo, portanto, as variações de disponibilidade determinadas por fatôres extrínsecos; na área II verifica-se paralelismo entre produção total e abundância relativa, sendo, dêsse modo, as variações de disponibilidade determinadas por fatôres intrínsecos. Um dêsses fatôres intrínsecos poderia ser a maior ou menor dispersão de concentração da corvina, como já foi verificado (Vazzoler, 1963), ao longo da área II, durante o ano.

$O$ acentuado desnível na produção por unidade de esfôrço, verificado entre as duas áreas (Vazzoler \& Sá, op. cit.), não é devido sòmente às diferenças de eficiência dos aparelhos, mas, prinpalmente, aos distintos níveis de abundância relativa das duas áreas.

Tudo indica que a queda na produção por unidade de esfôrço, verificada de ano para ano, nas duas áreas (Vazzoler \& Sá, op. cit.), é determinada pela queda da abundância relativa, queda esta mais acentuada na área II.

A resposta diferente do estoque, nas duas áreas, em relação à intensidade de pesca, associado a outros fatôres, como por exemplo, padrões de migração (verificados apenas para a corvina da área II (Vazzoler, op. cit.) e níveis bem distintos de abundância relativa nas duas áreas, vêm fortalecer a suposição da existência de dois estoques de corvina ao longo da área estudada; o estoque da área I, explorado há longo tempo, já teria alcançado um estado de equilíbrio com a pesca, dependendo as variações de produção apenas da intensidade de pesca e, o estoque da área II, cuja exploração é mais recente, ainda não teria alcançado êsse estado de equilíbrio, daí a queda acentuada da abundância relativa e a relação da produção com as variações da mesma.

\section{CONCLUSOEES}

1 - Há tendência de aumento da abundância relativa do início para o fim de cada ano, e de queda da mesma de ano para ano, nas duas áreas; essa queda é muito mais acentuada para a área II.

2 - Os níveis de abundância nas duas áreas são bem diferentes, sendo mais elevados na área II.

3 - Durante o ano há variações de disponibilidade, devido, na área I, a fatôres extrínsecos, e na área II, a fatôres intrínsecos. 
4 - Verificou-se resposta diferente do estoque, nas duas áreas, em relação à intensidade de pesca, fortalecendo a suposição da existência de dois estoques de corvina ao longo da área estudada; o estoque da área I, já teria entrado em equilíbrio com a pesca, enquanto que o da área II, ainda não teria alcançado êsse estado.

\section{B I B L I O G R A F I A}

MARR, J. C.

1951. On the use of terms "abundance", "availability" and "apparent abundance” in fishery biology. Copeia, n.: 2, p. 163-169.

Shimada, B. M. \& Schaefer, M. B.

1956. A study of changes in fishing effort, abundance, and yeld for yellow-fin and skipjack tuna in the, eastern Tropical Pacific Ocean. Bull. inter-Am. trop. Tuna Commn, vol. 1, n. ${ }^{\circ} 7$, p. 351469.

VAZzoler, A. E. A. DE M.

1963. Deslocamentos sazonais da corvina relacionados com as massas de água. Contrçōes Inst. oceanogr. Univ. S Paulo, ser. Ocean. Biol., n. ${ }^{\circ} 5,8$ p.

VAZZoler, A. E. A. DE M. \& SÁ, E. M. DE 1963. Análise da pesca da corvina na costa centro-sul do Brasil. Bolm Inst. oceanogr., S Paulo, vol. 13, n. ${ }^{\circ} 2$, p. 61-70. 